Aafke Elizabeth de Graaff Dave Anton Dongelmans Jan Maria Binnekade Evert de Jonge

\section{Clinicians' response to hyperoxia in ventilated patients in a Dutch ICU depends on the level of $\mathrm{FiO}_{2}$}

Received: 8 September 2009

Accepted: 12 March 2010

Published online: 28 September 2010

(C) The Author(s) 2010. This article is published with open access at

Springerlink.com

This article is discussed in the editorial available at: doi:

10.1007/s00134-010-2034-y.

A. E. de Graaff $(\bowtie)$ - D. A. Dongelmans .

J. M. Binnekade

Department of Intensive Care Medicine,

University of Amsterdam, Meibergdreef 9, 1105 AZ Amsterdam, The Netherlands e-mail: degraaff.a.e@gmail.com

Tel.: +31-205662509

Fax: $+31-205669568$

E. de Jonge

Department of Intensive Care Medicine,

Leiden University Medical Center,

Leiden, The Netherlands
Abstract Purpose: Hyperoxia may induce pulmonary injury and may increase oxidative stress. In this retrospective database study we aimed to evaluate the response to hyperoxia by intensivists in a Dutch academic intensive care unit. Methods: All arterial blood gas (ABG) data from mechanically ventilated patients from 2005 until 2009 were extracted from an electronic storage database of a mixed 32-bed intensive care unit in a university hospital in Amsterdam. Mechanical ventilation settings at the time of the ABG tests were retrieved. Results: The results of 126,778 ABG tests from 5,498 mechanically ventilated patients were retrieved including corresponding ventilator settings. In 28,222 (22\%) of the $\mathrm{ABG}$ tests the arterial oxygen tension $\left(\mathrm{PaO}_{2}\right)$ was $>16 \mathrm{kPa}$ $(120 \mathrm{mmHg}$ ). In only $25 \%$ of the tests with $\mathrm{PaO}_{2}>16 \mathrm{kPa}(120 \mathrm{mmHg})$ was the fraction of inspired oxygen $\left(\mathrm{FiO}_{2}\right)$ decreased. Hyperoxia was accepted without adjustment in ventilator settings if $\mathrm{FiO}_{2}$ was 0.4 or lower.

Conclusion: Hyperoxia is frequently seen but in most cases does not lead to adjustment of ventilator settings if $\mathrm{FiO}_{2}<0.41$. Implementation of guidelines concerning oxygen therapy should be improved and further research is needed concerning the effects of frequently encountered hyperoxia.

Keywords Mechanical ventilation . Hyperoxia - Guidelines .

Lung injury · Oxygen

\section{Introduction}

Mechanical ventilation (MV) provides essential life support for patients with respiratory failure. Unfortunately, this life support may cause or aggravate lung injury in acute respiratory distress syndrome (ARDS). Ventilator induced lung injury caused by repeated shear stress and barotrauma can be reduced using protective lung ventilation with lower tidal volumes [1]. The ARDS network study demonstrated a compelling survival advantage when using low tidal volumes rather than conventional MV in patients with acute lung injury (ALI) or ARDS [2]. This led to the reappraisal of the goals of ventilatory support, allowing some hypercapnia, in order to limit inspiratory pressures and to lower tidal volumes. Not only barotrauma due to MV, but also hyperoxia can induce lung injury. Many experimental studies have demonstrated increased levels of reactive oxygen-derived free radicals, with an influx of inflammatory cells, increased pulmonary permeability and endothelial cell injury with the use of a high fraction of inspired oxygen $\left(\mathrm{FiO}_{2}\right)$ [3] High inspiratory oxygen concentrations induce tissue hyperoxia and may mask pulmonary injury. Another detrimental effect of hyperoxia is the development of resorption atelectasis with increased shunting [4]. Accordingly, together with permissive hypercapnia, a certain extent of hypoxaemia is accepted. Generally a target arterial oxygen tension $\left(\mathrm{PaO}_{2}\right)$ of $>8 \mathrm{kPa}$ $(60 \mathrm{mmHg})$ is suggested [5]. A Canadian questionnaire study, however, found considerable variation in the 
attitudes, beliefs and practices of intensivists in the management of oxygen therapy. The responses suggested that most respondents believed that levels of $\mathrm{FiO}_{2}$ up to 0.4 are not harmful and that this is the ideal range of $\mathrm{FiO}_{2}$ when the $\mathrm{PaO}_{2}$ permits [6]. The actual response of intensivists to hyperoxia has never been studied. In this retrospective cohort study we aimed to study whether high $\mathrm{PaO}_{2}$ levels lead to adjustments in ventilator settings by intensivists in a Dutch academic intensive care unit (ICU).

\section{Methods}

Study centre

The Academic Medical Center (AMC) in Amsterdam is a teaching hospital where the ICU is a 32-bed "closed format" department in which medical and surgical patients (including cardiothoracic and neurosurgical patients) are under the direct care of the ICU team.

Patients and data collection

The study included all arterial blood gas (ABG) data from all mechanically ventilated patients from 2005 until 2009. Data were extracted automatically from the patient data management system (PDMS) storage database (Metavision, iMDsoft, Leiden, The Netherlands). Patients on noninvasive MV were excluded from the study. All patients received MV with an Evita4 ventilator (DrägerMedical, Best, The Netherlands) or a Galileo ventilator (Hamilton Medical, Rhäzüns, Switzerland). MV settings at the time of the ABG tests were retrieved. The following MV data were recorded: $\mathrm{FiO}_{2}$, measured positive endexpiratory pressure (PEEP) level, applied tidal volume (TV), inspiratory:expiratory (I:E) ratio and MV mode. Prone positioning, recruitment manoeuvres and other complementary measures that may improve oxygenation could not be explored in this database study. Every set of MV and ABG data was compared with the following set. The second set was then compared with the third, and so on. For every patient the last ABG test was excluded because no comparison was possible with a subsequent determination.

Demographic data were collected from the Dutch National Intensive Care Evaluation registry and included age, height, weight and acute physiological and chronic health evaluation (APACHE) II score. ABGs were determined routinely half an hour after every MV adjustment and also when blood glucose levels were measured. They were determined more frequently in patients without a good pulse oximetric saturation signal or on high pressure MV. All ABG test results were made available on the PDMS and were communicated to the clinician.

The predicted body weight (PBW) was calculated from the following formulas: in men, PBW $(\mathrm{kg})=50+$ 0.91(height in centimetres - 152.4); in women, PBW $(\mathrm{kg})=45.5+0.91$ (height in centimetres -152.4 ) [2]. In order to monitor the response to a certain extent of oxygenation we categorized the $\mathrm{ABG}$ test results into five $\mathrm{PaO}_{2}$ groups: $<8 \mathrm{kPa}(60 \mathrm{mmHg}), 8.01-10 \mathrm{kPa}$ (60-75 mmHg), $10.01-13 \mathrm{kPa}$ (75-98 mmHg), $13.01-$ $16 \mathrm{kPa}(98-120 \mathrm{mmHg})$, and $>16 \mathrm{kPa}(120 \mathrm{mmHg})$. For the purpose of this study the last group with a $\mathrm{PaO}_{2}$ $>16 \mathrm{kPa}(120 \mathrm{mmHg})$ was regarded as hyperoxic.

\section{MV protocol}

In the AMC a written MV protocol is available for all ICU physicians and nurses. Briefly, this protocol advises pressure-controlled MV or pressure-support MV. In addition, adaptive support ventilation is used on the Hamilton Galileo ventilator in patients with an uncomplicated postoperative course in whom extubation is expected within $24 \mathrm{~h}$. The MV protocol is based on an open lung concept [7]. MV is typically initiated with a $\mathrm{FiO}_{2}$ 0.4-0.6, PEEP $\geq 5 \mathrm{cmH}_{2} \mathrm{O}$ and $\mathrm{I}: \mathrm{E}$ ratio $1: 2$, with a target $\mathrm{PaO}_{2}$ higher than $10 \mathrm{kPa}(75 \mathrm{mmHg})$. PEEP and I:E ratio may be adjusted for lung recruitment if necessary. The $\mathrm{FiO}_{2}$ is targeted below 0.6. During procedures a higher $\mathrm{FiO}_{2}$ is accepted. Prone positioning is considered if the PEEP is $>10 \mathrm{cmH}_{2} \mathrm{O}$ and $\mathrm{FiO}_{2}$ is $>0.6$. The protocol suggests lowering $\mathrm{FiO}_{2}$ below 0.4 with a target $\mathrm{PaO}_{2}$ higher than $10 \mathrm{kPa}(75 \mathrm{mmHg})$. In the weaning phase, patients are candidates for discontinuation of $\mathrm{MV}$ if $\mathrm{FiO}_{2}$ is $\leq 0.4$, PEEP is $\leq 5 \mathrm{cmH}_{2} \mathrm{O}$ and no signs of respiratory distress are present. Manual hyperinflation is performed as part of standard airway care, after disconnection of the ventilator and after adjustment of MV settings. Recommended tidal volumes are between 6 and $8 \mathrm{ml} / \mathrm{kg}$ PBW. All blood gas results are shown to the physicians. As part of the team, nurses can decrease the $\mathrm{FiO}_{2}$ if the $\mathrm{PaO}_{2}$ is higher than $10 \mathrm{kPa}$ $\left(75 \mathrm{mmHg}\right.$ ), but all changes in $\mathrm{FiO}_{2}$ have to be reported to the physician. Nurses can make ventilator therapy recommendations, but unit policy mandates that all MV setting adjustments other than lowering of $\mathrm{FiO}_{2}$ are ordered by physicians. During the study period no changes in the MV protocol were made.

\section{Statistical analysis}

The statistical analysis was carried out with SPSS 16.01. An independent samples $t$-test, one-way ANOVA and the Kruskal-Wallis test were used as appropriate. Differences with a $p$ value $<0.05$ were considered significant. 


\section{Results}

A total of $148,136 \mathrm{ABG}$ test results were retrieved from the database, of which 126,778 were obtained during MV. These ABG tests related to 5,498 mechanically ventilated patients, of whom 4,880 were first admissions. The demographic data are shown in Table 1 . In $44 \%$ of the patients admission was after planned surgery. Trauma patients represented $4 \%$ of the study group. In the neurosurgery group $7 \%$ were elective patients and the others were admitted after urgent surgery for bleeding or trauma. Of the surgical patients almost $40 \%$ were ventilated for recovery from anaesthesia.

The baseline ventilator settings and adjustments together with subsequent oxygenation data for all ABG tests are shown in Table 2. Overall, approximately $40 \%$ of the ABG tests were performed during pressure-controlled MV with a median I:E ratio of 1:2. The mean tidal volume was $7.5 \pm 2.2 \mathrm{ml} / \mathrm{kg} \mathrm{PBW}$. In $57 \%$ of the ABG tests the $\mathrm{PaO}_{2}$ was between 8 and $13 \mathrm{kPa}(60-98 \mathrm{mmHg})$, in more than $40 \%$ the $\mathrm{PaO}_{2}$ was $>10 \mathrm{kPa}(75 \mathrm{mmHg})$, and in $22 \%$ the $\mathrm{PaO}_{2}$ was $>16 \mathrm{kPa}(120 \mathrm{mmHg})$. The median interval between two successive $\mathrm{ABG}$ tests was $166 \mathrm{~min}$ (interquartile range $100-258 \mathrm{~min}$ ). This decreased significantly with a lower $\mathrm{PaO}_{2}(P<0.001)$. The PEEP and $\mathrm{FiO}_{2}$ were not changed in most patients in any of the $\mathrm{PaO}_{2}$ groups.

To study the response to hyperoxia, we subcategorized the highest $\mathrm{PaO}_{2}$ group $(>16 \mathrm{kPa},>120 \mathrm{mmHg})$ based on the $\mathrm{FiO}_{2}$ (Table 3). In $57 \%$ of these ABG tests $\mathrm{FiO}_{2}$ was exactly 0.4 and $8 \%$ had $\mathrm{FiO}_{2}<0.4$. In only one-quarter (24.9\%) of the ABG tests was the $\mathrm{FiO}_{2}$ decreased. Of the total group with a $\mathrm{PaO}_{2}>16 \mathrm{kPa}(120 \mathrm{mmHg})$, at time of the successive $\mathrm{ABG}$ test $11 \%$ had $\mathrm{FiO}_{2}<0.4$, with a mean successive $\mathrm{PaO}_{2}$ of $18 \pm 5.9 \mathrm{kPa}(135 \pm 44 \mathrm{mmHg})$. At

Table 1 Patient characteristics of the study population

\begin{tabular}{ll}
\hline Characteristic & Value \\
\hline Age (years, mean \pm SD) & $61 \pm 16$ \\
Gender M/F (\%) & $64 / 36$ \\
Height (cm, mean \pm SD) & $174 \pm 9$ \\
Actual body weight $(\mathrm{kg}$, mean $\pm \mathrm{SD})$ & $78 \pm 6$ \\
Predicted body weight $(\mathrm{kg}, \text { mean } \pm \mathrm{SD})^{\mathrm{a}}$ & $67 \pm 10$ \\
APACHE II score (mean $\pm \mathrm{SD})$ & $19 \pm 8$ \\
Referring specialty $(\%)$ & \\
Cardiothoracic surgery & 37 \\
General surgery & 20 \\
Internal medicine & 12 \\
Neurosurgery & 11 \\
Cardiology & 9 \\
Other & 11 \\
Type of admission $(\%)$ & 37 \\
Medical & 19 \\
Unplanned surgery & 44 \\
Planned surgery & \\
\hline
\end{tabular}

${ }^{\text {a }}$ Men $=50+0.91$ (height in centimetres -152.4 ); women $=$ $45.5+0.91$ (height in centimetres -152.4 ) the time of the successive $\mathrm{ABG}$ test $64 \%$ had a $\mathrm{FiO}_{2}$ of exactly 0.4. In the subsequent $\mathrm{ABG}$ test $33 \%$ had PEEP above $5 \mathrm{cmH}_{2} \mathrm{O}$. In $78 \%$ of cases with $\mathrm{PaO}_{2}>16 \mathrm{kPa}$ $\left(120 \mathrm{mmHg}\right.$ ) and $\mathrm{FiO}_{2}<0.41$ neither $\mathrm{FiO}_{2}$ nor PEEP was adjusted (Table 4). In contrast, in most cases with $\mathrm{PaO}_{2}$ $>16 \mathrm{kPa}(120 \mathrm{mmHg})$ and $\mathrm{FiO}_{2}>0.4$, ventilator settings were adjusted.

\section{Discussion}

In this retrospective database study, we found that hyperoxia (defined as $\mathrm{PaO}_{2}>16 \mathrm{kPa}, 120 \mathrm{mmHg}$ ) was frequently present in patients but in most cases did not lead to adjustment of ventilator settings. If the $\mathrm{FiO}_{2}$ was 0.4 or lower the hyperoxia was accepted in the majority of cases.

Oxygen therapy has been used in the care of critically ill patients since the early years of the last century. However, from the beginning of the 1970s increasing understanding emerged that oxygen therapy can cause pulmonary toxicity [8]. Baboons were found to have progressive alveolar septal injury after exposure to $60 \%$ oxygen for 14 days and hyperoxia $\left(\mathrm{FiO}_{2} 0.5\right)$ exacerbated lung injury in a large tidal volume model in rabbits $[9$, 10]. The acute lung injury caused by hyperoxia is characterized by an influx of inflammatory cells representing an alteration in barrier properties of the alveolar capillary membrane [3]. The systemic effects of hyperoxia are less clear [11]. Some work has suggested that there is an important interaction between $\mathrm{FiO}_{2}$ and pulmonary free radicals potentially leading to an adverse effect on outcome in ARDS [12]. More recently, Li et al. [13] found in mice that the combined detrimental effect of oxygen and repetitive cyclic stretch results in the activation of specific independent intracellular signalling pathways, showing that hyperoxia-induced lung injury is more than free radical-mediated injury alone. Despite extensive experimental evidence in animals supporting a direct injurious effect of high inspired oxygen concentrations, only few human data exist on this topic. In 1992 a small study in 12 healthy nonsmoking adults exposed to a fractional inspired oxygen concentration of $50 \%$ (mean exposure $44 \mathrm{~h}$ ) showed enhanced oxidative stress and stimulation of alveolar macrophages in bronchoalveolar lavage fluid [14]. Little is known about the dose range of oxygen toxicity. A recent study in Wistar rats found a dose-dependent hyperoxic lung injury [15]. However, to our knowledge no studies about the safety of an inspired oxygen concentration below $40 \%$ have been performed. Moreover, until now no studies concerning oxygen toxicity have been conducted in critically ill patients [16].

The fact that neither physicians nor nurses adjusted ventilator settings in the event of hyperoxia would be understandable if other clinical signs indicated 
Table 2 Oxygenation data, ventilator settings and adjustments for all ABG tests

\begin{tabular}{|c|c|c|c|c|c|c|c|c|c|}
\hline $\begin{array}{l}\mathrm{PaO}_{2} \\
\text { category } \\
(\mathrm{kPa})\end{array}$ & $n(\%)$ & $\begin{array}{l}\mathrm{PaO}_{2} \\
(\mathrm{kPa}, \\
\text { mean } \pm \mathrm{SD})\end{array}$ & $\mathrm{FiO}_{2}$ & $\begin{array}{l}\text { PEEP } \\
\left(\mathrm{cmH}_{2} \mathrm{O}\right)\end{array}$ & $\begin{array}{l}\text { Time } \\
\text { until next } \\
\text { ABG } \\
\text { test (min) }\end{array}$ & $\begin{array}{l}\text { Delta } \\
\mathrm{FiO}_{2}{ }^{\mathrm{a}}\end{array}$ & $\begin{array}{l}\text { Delta } \\
\text { PEEP } \\
\left(\mathrm{cmH}_{2} \mathrm{O}\right)^{\mathrm{a}}\end{array}$ & $\begin{array}{l}\text { Delta } \\
\mathrm{PaO}_{2}(\mathrm{kPa}) \\
\text { mean } \pm \mathrm{SD})^{\mathrm{a}}\end{array}$ & $\begin{array}{l}\text { No } \\
\text { decrease } \\
\text { in } \mathrm{FiO}_{2} \\
\text { or } \mathrm{PEEP} \text {, } \\
n(\%)\end{array}$ \\
\hline o & 4,54 & & 0.5 & 10 & & & & & $9(83)$ \\
\hline $8.01-10$ & $21,335(16.8)$ & $9.2 \pm 0.6$ & $0.45(0.4-0.51)$ & $9(5-12)$ & $143(87-228)$ & $0(0$ & $0(0$ & 3.2 & $17,071(80)$ \\
\hline $10.01-13$ & $45,545(35.9)$ & $11.5 \pm 0.8$ & $0.4(0.4-0.5)$ & $8(5-10)$ & $174(108-264)$ & $0(0-0)$ & $0(0-0)$ & $0.6 \pm 3.1$ & 32,973 (72) \\
\hline $13.01-16$ & $27,132(21.4)$ & $14.4 \pm 0.9$ & $0.4(0.4-0.42)$ & $5(5-10)$ & $181(111-276)$ & $0(0-0)$ & $0(0-0)$ & $-0.4 \pm 3.4$ & $18,297(67)$ \\
\hline$>16.01$ & $28,222(22.3)$ & $20.7 \pm 6.0$ & $0.4(0.4-0.45)$ & $5(5-10)$ & $166(99-261)$ & $0(0-0)$ & $0(0-0)$ & $-2.6 \pm 6.4$ & $17,527(62)$ \\
\hline
\end{tabular}

Data are presented as medians (interquartile range) unless otherwise stated

${ }^{a}$ Delta difference between successive ABG tests

Table 3 Oxygenation data, ventilator settings and adjustments in subcategory with $\mathrm{PaO}_{2}>16 \mathrm{kPa}$

\begin{tabular}{llllcrr}
\hline $\mathrm{FiO}_{2}$ & $n(\%)$ & $\begin{array}{l}\mathrm{PaO}_{2} \\
(\mathrm{kPa}, \text { mean } \pm \mathrm{SD})\end{array}$ & $\begin{array}{l}\mathrm{PEEP} \\
\left(\mathrm{cmH}_{2} \mathrm{O}\right)\end{array}$ & Delta $\mathrm{FiO}_{2}{ }^{\mathrm{b}}$ & $\begin{array}{l}\text { Delta PEEP } \\
(\mathrm{cmH})^{\mathrm{b}}\end{array}$ & $\begin{array}{l}\text { Delta PaO} \\
(\mathrm{kPa}, \mathrm{mean} \pm \mathrm{SD})^{\mathrm{b}}\end{array}$ \\
\hline $0.21-0.4^{\mathrm{a}}$ & $18,287(65)$ & $19.8 \pm 3.6$ & $5(5-6)$ & $0(0-0)$ & $0(0-0)$ & $-1.5 \pm 4.5$ \\
$0.41-0.6$ & $8,451(30)$ & $21.1 \pm 5.7$ & $8(5-10)$ & $-0.05(-0.1$ to 0$)$ & $0(0-0)$ & $-3.8 \pm 6.4$ \\
$0.61-0.8$ & $866(3)$ & $23.8 \pm 8.2$ & $12(10-15)$ & $-0.15(-0.2$ to 0.1$)$ & $0(0-0)$ & $-7.3 \pm 8.6$ \\
$0.81-1.0$ & $618(2)$ & $38.9 \pm 18.9$ & $10(5-15)$ & $-0.3(-0.5$ to -0.15$)$ & $0(0-0)$ & $-17.4 \pm 18$ \\
\hline
\end{tabular}

Data are presented as medians (interquartile range) unless otherwise stated

${ }^{\text {a }}$ In $88 \%$ of this group $\mathrm{FiO}_{2}=0.4$

b Delta difference between successive ABG tests

Table 4 Ventilator adjustments in subcategory with $\mathrm{PaO}_{2}>16 \mathrm{kPa}$

\begin{tabular}{llll}
\hline $\mathrm{FiO}_{2}$ & $\begin{array}{l}\text { Decreased } \\
\mathrm{FiO}_{2}, n(\%)\end{array}$ & $\begin{array}{l}\text { Decreased } \\
\text { PEEP, } n(\%)\end{array}$ & $\begin{array}{l}\text { No decrease in FiO } \\
\text { or PEEP, } n(\%)\end{array}$ \\
\hline $0.21-0.4^{\mathrm{a}}$ & $998(6)$ & $3,090(17)$ & $14,289(78)$ \\
$0.41-0.6$ & $4,810(57)$ & $1,798(21)$ & $2,994(35)$ \\
$0.61-0.8$ & $715(83)$ & $174(20)$ & $130(15)$ \\
$0.81-1.0$ & $496(81)$ & $105(17)$ & $114(18)$
\end{tabular}

${ }^{\mathrm{a}}$ In $88 \%$ of this group $\mathrm{FiO}_{2}=0.4$

deterioration of pulmonary function. In our study, however, this is a very unlikely explanation given the fact that mean $\mathrm{PaO}_{2}$ in the subsequent $\mathrm{ABG}$ test was still $18 \mathrm{kPa}$ $(135 \mathrm{mmHg})$. Another potential but unlikely explanation would be that physicians and ICU nurses prefer some level of hyperoxia because monitoring of arterial oxygenation is performed relatively infrequently. We found a median duration between $\mathrm{ABG}$ tests of 166 min, which is equal to almost nine $\mathrm{ABG}$ analyses per patient-day.

Significantly more ABG samples were taken in the group with a $\mathrm{PaO}_{2}$ below $8 \mathrm{kPa}(60 \mathrm{mmHg})$. This is more frequent than described in the past. In 1997, a study found that after the implementation of a practice guideline for ABG measurement, the number of tests decreased from 4.9 to $2.4 \mathrm{ABG}$ tests per patient-day [17]. In a Swiss study the frequency decreased after a guideline from 8.2 to 4.8 tests per patient-day [18]. The high number of ABG tests in this study may be explained by the fact that blood glucose was also measured in the blood gas analyser. Nevertheless, in these cases ABG data were also presented to the clinician. In addition to frequent $A B G$ analysis, oxygen saturation is also continuously monitored transcutaneously in all our patients. Rice et al. [19] demonstrated in a medical patient population that pulse oximetric saturation/ $/ \mathrm{FiO}_{2}$ correlates with $\mathrm{PaO}_{2} / \mathrm{FiO}{ }_{2}$ ratios, and thus may serve as a surrogate for the follow-up of mechanically ventilated critically ill patients. Thus, unnoticed hypoxaemia is unlikely to occur and there seems to be no reason for preferring some level of hyperoxia. 
In our study, many patients were admitted after elective surgery, recovering from anaesthesia. These patients may have been disconnected from the ventilator when $\mathrm{PaO}_{2}$ was high and $\mathrm{FiO}_{2}$ was 0.4 . However, as only ABG tests were included when patients were on mechanical ventilation, this is no explanation for our findings. Furthermore, some patients had a very high $\mathrm{FiO}_{2}(0.81-1.0)$ as well as a high mean $\mathrm{PaO}_{2}$ of $39 \mathrm{kPa}$ (Table 3). This group only represents $0.5 \%$ of the total group of $\mathrm{ABG}$ tests. Explanations for unusually high $\mathrm{PaO}_{2}$ values may include dysfunctioning pulse oximetric saturation measurements leading to high $\mathrm{FiO}_{2}$, treatment for $\mathrm{CO}$ intoxication or hyperoxygenation during or after tracheal suction.

High $\mathrm{PaO}_{2}$ values only led to adjustment of inspired oxygen concentration if $\mathrm{FiO}_{2}$ was higher than 0.4. Our protocol mandates a target $\mathrm{PaO}_{2}$ above $10 \mathrm{kPa}$ $\left(75 \mathrm{mmHg}\right.$ ) and suggests decreasing the $\mathrm{FiO}_{2}$ to 0.21 if the $\mathrm{PaO}_{2}$ is above $10 \mathrm{kPa}(75 \mathrm{mmHg})$. Furthermore, $33 \%$ of the group with $\mathrm{PaO}_{2}>16 \mathrm{kPa}(120 \mathrm{mmHg})$ still had PEEP above $5 \mathrm{cmH}_{2} \mathrm{O}$ in the subsequent $\mathrm{ABG}$ test. Previous reports from our institution show that feedback and education improve physician compliance in the use of lung-protective MV [20]. It seems very likely that feedback, education and adjusted protocols concerning oxygenation will improve the weaning to a minimal $\mathrm{FiO}_{2}$ of 0.21 and minimal PEEP level. Apparently, physicians and nurses do not consider hyperoxia as potentially hazardous if $\mathrm{FiO}_{2}$ is lower than 0.41 and do not adjust ventilator settings in these circumstances. Interestingly, in a questionnaire study from 1999, similar attitudes were reported among Canadian intensivists. Whereas high oxygen saturation measurements would urge intensivists to lower $\mathrm{FiO}_{2}$ in almost all cases when $\mathrm{FiO}_{2}$ was higher than 0.4 , only $54 \%$ of respondents would alter oxygen administration if $\mathrm{FiO}_{2}$ was lower than 0.4 [6].

Our study is the first to reveal adjustments of ventilator settings by intensivists and ICU nurses in the event of hyperoxia in intensive care patients. The main limitation of this study was the fact that it was a single-centre study. We do not know whether responses to hyperoxia are the same in other ICUs in the Netherlands or other countries. Another limitation of this study is that the clinical condition of the patient may influence decisions to change ventilator settings and that no information on the condition of the patients was available for this analysis. Also, we do not know whether hyperoxia is detrimental in critically ill patients, e.g. by increasing the severity of lung injury.

\section{Conclusion}

Hyperoxia was frequently present in ICU patients but in most cases did not lead to adjustment of ventilator settings. If $\mathrm{FiO}_{2}$ was 0.4 or lower the hyperoxia was accepted in the majority of cases. Further research is needed concerning the effects of frequently encountered hyperoxia in ICU patients. For now and given the experimental evidence of hyperoxia-induced damage, it seems wise to emphasize in guidelines that hyperoxia should be limited to what is needed to ensure adequate tissue oxygenation.

Acknowledgments The authors would like to thank Mark de Jong for acquisition of the data from PDMS.

Conflict of interest The authors have no conflict of interest to declare.

Open Access This article is distributed under the terms of the Creative Commons Attribution Noncommercial License which permits any noncommercial use, distribution, and reproduction in any medium, provided the original author(s) and source are credited.

\section{References}

1. Pinhu L, Whitehead T, Evans T, Griffiths M (2003) Ventilatorassociated lung injury. Lancet 361:332-340

2. Acute Respiratory Distress Syndrome Network (2000) Ventilation with lower tidal volumes as compared with traditional tidal volumes for acute lung injury and the acute respiratory distress syndrome. N Engl J Med 342:1301-1308

3. Bhandari V, Elias JA (2006) Cytokines in tolerance to hyperoxia-induced injury in the developing and adult lung. Free Radic Biol Med 41:4-18
4. Aboab J, Jonson B, Kouatchet A, Taille S, Niklason L, Brochard L (2006) Effect of inspired oxygen fraction on alveolar derecruitment in acute respiratory distress syndrome. Intensive Care Med 32:1979-1986

5. Tobin MJ (1994) Mechanical ventilation. N Engl J Med 330:1056-1061

6. Mao C, Wong DT, Slutsky AS, Kavanagh BP (1999) A quantitative assessment of how Canadian intensivists believe they utilize oxygen in the intensive care unit. Crit Care Med 27:2806-2811
7. Lachmann B (1992) Open up the lung and keep the lung open. Intensive Care Med 18:319-321

8. Jackson RM (1985) Pulmonary oxygen toxicity. Chest 88:900-905

9. Crapo JD, Hayatdavoudi G, Knapp MJ, Fracica PJ, Wolfe WG, Piantadosi CA (1994) Progressive alveolar septal injury in primates exposed to $60 \%$ oxygen for 14 days. Am J Physiol 267:L797-L806

10. Sinclair SE, Altemeier WA, MatuteBello G, Chi EY (2004) Augmented lung injury due to interaction between hyperoxia and mechanical ventilation. Crit Care Med 32:2496-2500 
11. Kavanagh BP (1998) Goals and concerns for oxygenation in acute respiratory distress syndrome. Curr Opin Crit Care 4:16-20

12. Quinlan GJ, Lamb NJ, Tilley R, Evans TW, Gutteridge JMC (1997) Plasma hypoxanthine levels in ARDS: implications for oxidative stress, morbidity and mortality. Am J Respir Crit Care Med 155:479-484

13. Li LF, Liao SK, Ko YS, Lee CH, Quinn DA (2007) Hyperoxia increases ventilator-induced lung injury via mitogen-activated protein kinases: a prospective, controlled animal experiment. Crit Care 11:R25

14. Griffith DE, Garcia JG, James HL, Callahan KS, Iriana S, Holiday D (1992) Hyperoxic exposure in humans. Effects of 50 percent oxygen on alveolar macrophage leukotriene B4 synthesis. Chest 101:392-397

15. Nagato A, Silva FL, Silva AR, Bezerra FS, Oliveira ML, Belló-Klein A, Porto LC, Valenca SS (2009) Hyperoxiainduced lung injury is dose dependent in Wistar rats. Exp Lung Res 35:713-728
16. Altemeier WA, Sinclair SE (2007) Hyperoxia in the intensive care unit: why is more not always better. Curr Opin Crit Care 13:73-78

17. Pilon CS, Leathley M, London R, McLean S, Phang PT, Priestley R, Rosenberg FM, Singer J, Anis AH, Dodek PM (1997) Practice guideline for arterial blood gas measurement in the intensive care unit decreases numbers and increases appropriateness of tests. Crit Care Med 25:1308-1313

18. Merlani P, Garnerin P, Diby M, Ferring M, Ricou B (2001) Linking guideline to regular feedback to increase appropriate requests for clinical tests: blood gas analysis in intensive care. BMJ 323:620-624

19. Rice TW, Wheeler AP, Bernard GR, Hayden DL, Schoenfeld DA, Ware LB (2007) Comparison of the SpO2/FiO2 ratio and the $\mathrm{PaO} 2 / \mathrm{FiO} 2$ ratio in patients with acute lung injury or ARDS. Chest 132:410-417
20. Wolthuis EK, Korevaar JC, Spronk P, Kuiper MA, Dzoljic M, Vroom MB, Schultz MJ (2005) Feedback and education improve physician compliance in use of lung-protective mechanical ventilation. Intensive Care Med 31:540-546 